\title{
Navigating the uncharted waters of combination therapy in pulmonary arterial hypertension: COMPASS or dead-reckoning
}

\author{
Jean-Luc Vachiery ${ }^{1}$ and Lewis J. Rubin ${ }^{2}$ \\ Affiliations: ${ }^{1}$ Pulmonary Vascular Diseases Clinic, Dept of Cardiology, Cliniques Universitaires de Bruxelles - \\ Hôpital Erasme, Brussels, Belgium. ${ }^{2}$ Division of Pulmonary and Critical Care Medicine, University of
} California San Diego School of Medicine, La Jolla, CA, USA.

Correspondence: Jean-Luc Vachiery, Pulmonary Vascular Diseases Clinic, Dept of Cardiology, Cliniques Universitaires de Bruxelles - Hôpital Erasme, Brussels, Belgium. E-mail: jeanluc.vachieryđerasme.ulb.ac.be

\footnotetext{
-
}

@ERSpublications

Two studies in this month's ERJ report results of combination therapy for PAH http://ow.ly/OlgID

Despite substantial advances in the treatment of pulmonary arterial hypertension (PAH) over the past two decades, with 13 drugs approved by regulatory agencies worldwide, the responses to medical therapy are often incomplete or unsatisfactory [1]. As with other conditions with complex pathogenesis, $\mathrm{PAH}$ is probably the result of multiple stimuli, both genetic and epigenetic, whose interplay over the course of the disease is poorly understood. Combination therapy trials in cancer, heart failure and HIV infection have demonstrated the value of targeting multiple pathogenic pathways in complex diseases, and this strategy has become the therapeutic mainstay for these chronic conditions. Unlike these common diseases, however, $\mathrm{PAH}$ is considered an "orphan" disease, making large-scale clinical trials of multiple therapies more challenging, both logistically and practically $[2,3]$. Two articles in this issue of the European Respiratory Journal provide new information regarding the effects of adding a second approved oral medication to PAH patients who are not achieving a satisfactory clinical response to initial oral monotherapy $[4,5]$.

The COMPASS trial [4] enrolled 334 subjects over 6 years who were failing on first line therapy with sildenafil into a randomised trial to receive either the addition of bosentan $125 \mathrm{mg}$ twice daily or placebo. The primary end-point was the time to first composite end-point of morbidity and mortality. There was no difference between the groups in the time to the primary end-point, and there were only modest differences in placebo-adjusted 6 -min walk distance $(+21 \mathrm{~m})$ and $\mathrm{N}$-terminal pro-brain natriuretic peptide (NT-ProBNP) in favour of the combination therapy group.

The study reported by DARDI et al. [5] was an open label single-centre observational trial performed over 10 years in which subjects receiving first-line monotherapy with either sildenafil or bosentan then received the addition of the other drug if they failed to meet pre-specified treatment goals. While there was no pre-specified primary end-point of this study, the authors report the survival and describe improvements compared to baseline in exercise capacity, haemodynamics and symptoms in their cohort after treatment with combination therapy.

Taken together, the results of these two studies leave us with a "cup half-full" feeling. Most disappointing is the COMPASS trial, which expended precious resources for a study that took far too long to complete enrolment - a problematic signal of design issues at the onset - and was underpowered to detect a meaningful treatment effect based on our current knowledge from larger time-to-clinical worsening end-point clinical trials in PAH. A likely important contributor to the negative outcome of COMPASS was the unproven primary end-point component of a patient self-assessment of status, although this has been

Received: June 092015 | Accepted after revision: June 102015

Conflict of interest: Disclosures can be found alongside the online version of this article at erj.ersjournals.com

Copyright OERS 2015 
widely used in heart failure clinical trials. It is not surprising that "trial fatigue" contributed to an element of self-reported unchanged or worsening status in both treatment arms after a prolonged participation in a blinded treatment trial. Finally, the high proportion of subjects enrolled in COMPASS with comorbid cardiopulmonary conditions raises the likelihood that the enrolled cohort did not comprise a homogeneous PAH cohort, and that many subjects had either other forms of pulmonary hypertension that are less likely to respond to PAH-targeted therapy or experienced sufficient morbidities from the concomitant illnesses to mask a PAH treatment effect.

While the study by DARDI et al. [5] took a more "dead-reckoning" approach, i.e. seeking what the authors identified as a safe harbour and then reporting the success rate of achieving it, rather than performing a randomised, placebo-controlled blinded trial with pre-specified end-points, it nevertheless provides some evidence in support of add-on combination therapy when patients fail to improve with monotherapy. It should be emphasised, however, that improvements in exercise capacity and symptoms are soft end-points when subjects serve as their own controls in unblinded trials, and changes in biomarkers of disease severity such as haemodynamic parameters and NT-ProBNP are not necessarily surrogates of improved outcome.

While the evidence for add-on therapy with an endothelin-receptor antagonist and phosphodiesterase type 5 inhibitor is not definitive based on the two studies reported in this issue, they do provide a rationale and guidance for better-designed studies in the future. There is ample evidence from published studies that add-on therapy to background monotherapy using sildenafil (PACES), inhaled treprostinil (TRIUMPH) and riociguat (PATENT) improve short-term end-points including exercise capacity and haemodynamics [1]. In addition, recently completed large-scale trial results have been presented demonstrating that initial combination therapy with ambrisentan plus tadalafil (AMBITION) reduced the time to clinical failure events [6], and the addition of macitentan (SERAPHIN) [7] or selexipag (GRIPHON) [8] reduced the time to morbidity and mortality events in both treatment-naïve subjects and those receiving background therapies.

Thus, there is little question that combination therapy is effective in PAH. The goal should now be how to best demonstrate it in clinical trials that both mimic the real world and employ best clinical trial design.

\section{References}

1 Humbert M, Lau EM, Montani D, et al. Advances in therapeutic interventions for patients with pulmonary arterial hypertension. Circulation 2014; 130: 2189-208.

2 Lagakos SW. Clinical trials and rare diseases. N Engl J Med 2003; 348: 2455-2456.

3 Haffner ME. Adopting orphan drugs - two dozen years of treating rare diseases. N Engl J Med 2006; 354: 445-447.

4 McLaughlin V, Channick RN, Ghofrani HA, et al. Bosentan added to sildenafil therapy in patients with pulmonary arterial hypertension. Eur Respir J 2015; 46: 405-413.

5 Dardi F, Manes A, Palazzini M, et al. Combining bosentan and sildenafil in pulmonary arterial hypertension patients failing monotherapy: real-world insights. Eur Respir J 2015; 46: 414-421.

6 Galie N, Barbera JA, Frost AE, et al. Initial use of ambrisentan plus tadalafil in pulmonary arterial hypertension. N Engl J Med 2015; [In press].

7 Pulido T, Adzerikho I, Channick RN, et al. Macitentan and morbidity and mortality in pulmonary arterial hypertension. N Engl J Med 2013; 369: 809-818.

8 McLaughlin VV, Channick R, Chin KM, et al. Effect of selexipag on morbidity/mortality in pulmonary arterial hypertension: results of the GRIPHON study. J Am Coll Cardiol 2015; 65: Suppl. A, A380. 